\title{
Haptoglobin as a Biomarker
}

\author{
S. N. Naryzhny ${ }^{a, b}$, * and O. K. Legina ${ }^{b}$ \\ ${ }^{a}$ Institute of Biomedical Chemistry, ul. Pogodinskaya 10, Moscow, 119121 Russia \\ ${ }^{b}$ St-Petersburg Nuclear Physics Institute (PNPI) NRC Kurchatov Institute, \\ Orlova Roshcha 1, Gatchina, Leningrad oblast, 188300 Russia \\ *e-mail: snaryzhny@mail.ru
}

Received February 4, 2021; revised March 5, 2021; accepted March 5, 2021

\begin{abstract}
Haptoglobin $(\mathrm{Hp})$ is a glycoprotein that binds free hemoglobin $(\mathrm{Hb})$ in plasma and plays a critical role in tissue protection and prevention of oxidative damage. Besides, it has some regulatory functions. Haptoglobin is an acute-phase protein, its concentration in plasma changes in pathology, and the test for its concentration is part of normal clinical practice. Haptoglobin is a conservative protein synthesized mainly in the liver and lungs and is the subject of research as a potential biomarker of many diseases, including various forms of malignant neoplasms. Haptoglobin has several unique biophysical characteristics. The human $H p$ gene is polymorphic, has three structural alleles that control the synthesis of three major phenotypes of haptoglobin: homozygous Hp1-1 and Hp2-2, and heterozygous Hp2-1, determined by a combination of allelic variants that are inherited. Numerous studies indicate that the phenotype of haptoglobin can be used to judge the individual predisposition of a person to various diseases. In addition, Hp undergoes various post-translational modifications (PTMs). These are structural transformations (removal of the signal peptide, cutting off the Pre-Hp precursor molecule into two subunits, $\alpha$ and $\beta$, limited proteolysis of $\alpha$-chains, formation of disulfide bonds, multimerization), as well as chemical modifications of $\alpha$-chains and glycosylation of the $\beta$-chain. Glycosylation of the $\beta$-chain of haptoglobin at four Asn sites is the most important variable PTM that regulates the structure and function of the glycoprotein. The study of modified oligosaccharides of the $\beta$-chain of $\mathrm{Hp}$ has become the main direction in the study of pathological processes, including malignant neoplasms. These characteristics indicate the possibility of the existence of $\mathrm{Hp}$ in the form of a multitude of proteoforms, probably performing different functions. This review is devoted to the description of the structural and functional diversity and the potential use of $\mathrm{Hp}$ as a biomarker of various pathologies.
\end{abstract}

Keywords: haptoglobin, biomarker

DOI: $10.1134 / \mathrm{S} 1990750821030069$

\section{INTRODUCTION}

Haptoglobin $(\mathrm{Hp})$, a conservative protein that presents in all mammals, was discovered in 1938 "as a substance in blood plasma that binds hemoglobin" [1]. Accordingly, its name was formed from the combination of the words "haptein" (Greek for "to bind") and "hemoglobin" $(\mathrm{Hb})$. Hp forms an extremely strong non-covalent complex with free $\mathrm{Hb}(1: 1 \mathrm{~mol} / \mathrm{mol})$, which protects tissues from oxidative damage [2]. Haptoglobin is multifunctional, plays an important role in various biological processes, and is currently considered as a potential biomarker of many diseases, including various forms of malignant neoplasms. Also,

Abbreviations used: a.a. - amino acid residues; $\mathrm{CCP}-$ the complement control protein; COPD-chronic obstructive pulmonary disease; 2DE-two-dimensional electrophoresis; $\mathrm{Hp}-$ haptoglobin; $\mathrm{Hb}$-hemoglobin; LDL-low-density lipoproteins; MASP-mannose-binding lectin-associated serine proteinase; MS-mass spectrometry; PTM-post-translational modification; Pre-Hp-pre-haptoglobin; TLF-1-trypanosomal lytic factor-1.
Hp exhibits immunoregulatory properties, participates in the inhibition of nitric oxide, stimulates tissue repair, is involved in angiogenesis, etc. The concentration of $\mathrm{Hp}$ in plasma changes with pathology and the test for its concentration is part of normal clinical practice.

\section{HAPTOGLOBIN GENE(S)}

Only human $\mathrm{Hp}$ is characterized by molecular heterogeneity due to genetic polymorphism. In humans, the gene $H p$ is located on chromosome 16 and can be present in the form of three alleles: $H p 1 F, H p 1 S$, $H p 2$, which control the formation of six $\mathrm{Hp}$ phenotypes: $1 \mathrm{~F}-1 \mathrm{~F}, 1 \mathrm{~S}-1 \mathrm{~S}, 1 \mathrm{~F}-1 \mathrm{~S}, 2-1 \mathrm{~F}, 2-1 \mathrm{~S}, 2-2$, [3-5]. Due to the lack of a functional difference between $H p 1 F$ and $H p 1 S$, which differ only in point mutations, only two alleles, $H p 1$ and $H p 2$, are often considered, which manifest themselves as three phenotypes: homozygous Hp1-1 and Hp2-2, and heterozygous Hp2-1 depending on the combination of inherited allelic variants. It 


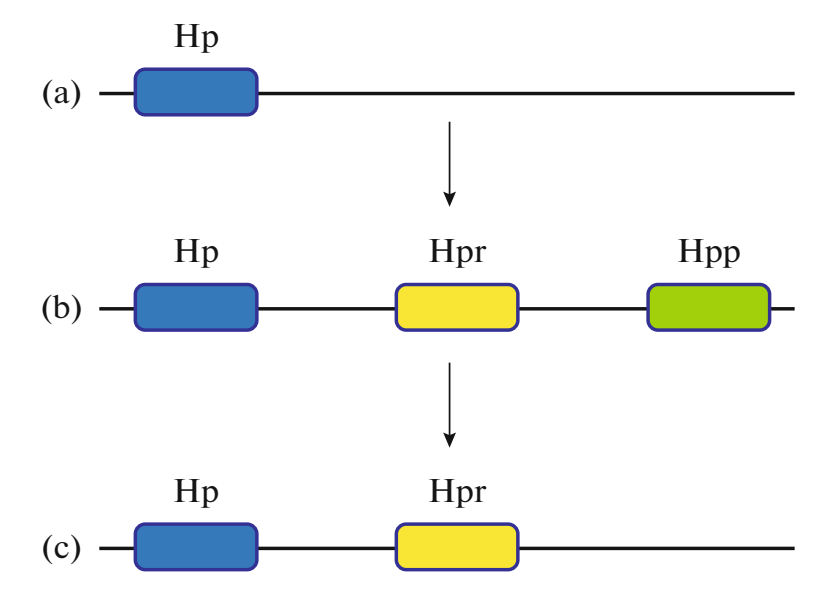

Fig. 1. Schematic representation of the evolution of the haptoglobin gene cluster. The $\mathrm{Hpr}$ gene arose because of the three-fold repetition of the $H p$ gene after the New World monkeys moved away from other primates. Thus, new world monkeys (a), such as the spider monkey, carry only one $H p$ gene, whereas Old World monkeys (b), of which the chimpanzee is an example, possess the $H p$ and $H p r$ genes in addition to the so-called primate haptoglobin gene ( $H p p)$. During human evolution (c), one locus was removed, and only 2 genes ( $\mathrm{Hp}$ and $\mathrm{Hpr}$ ) remained.

is assumed that the $\mathrm{Hp} 2$ allele arose as a result of intragenic duplication of a $1700 \mathrm{bp}$ DNA fragment of gene Hpl after human divergence in the late evolution of primates [6].

The estimated frequency of different types of haptoglobin is as follows: $\mathrm{Hp} 1-1-15-18 \%$; $\mathrm{Hp} 2-1-46 \%$; $\mathrm{Hp} 2-2-38 \%$, but significant geographical differences were noted. For example, in Southeast Asia, the frequency of the $H p 1$ allele is only about 0.1 , while in other regions, it can reach about 0.8 (South America). The observed differences in the distribution of $\mathrm{Hp}$ phenotypes are probably the result of both genetic drift and natural selection [7]. Some methods of forensic medicine are even based on this, for example, to establish controversial paternity [8].

It should be noted that primates have two more genes derived from the gene $\mathrm{Hp}-\mathrm{Hpr}$ and $\mathrm{Hpp}$ (Fig. 1). The $H p r$ gene is $90 \%$ identical to the $H p$ gene and is located on the same chromosome at a distance of only $2200 \mathrm{bp}$, after another $16000 \mathrm{bp}$ the Hpp gene is located. The $\mathrm{Hpr}$ and $\mathrm{Hpp}$ genes appear to have arisen as a result of the triplication of the $H p$ gene during primate evolution. Subsequently, the Hpp gene in humans was deleted, and only two genes remained in the current cluster of human $H p$ genes [9].

In humans, haptoglobin is synthesized mainly in the liver and lungs and is secreted into the blood plasma [10], but its mRNA is also detected in the kidneys, spleen, thymus, and heart [11]. The expression level of the $\mathrm{Hpr}$ gene is 1000 times lower than that of $H p$. $H p r$, like $H p$, is also expressed mainly in the liver, but in addition to this, its mRNA is found in many other organs (https://www.uniprot.org/uniprot/ P00739).

Analysis of the homology of genomic sequences showed that teleosts are an utmost member of the phylogenetic series with a gene that encodes a protein homolog of mammalian haptoglobin. These results suggest that $\mathrm{Hp}$ evolved from a complement-associated protein (mannose-binding lectin-associated serine proteinase, MASP) with the advent of fish. The exception was the chicken and the frog, they lack this gene. However, another protein that binds $\mathrm{Hb}$ and is a potent antioxidant, PIT54, was identified in chicken plasma [12].

\section{STRUCTURAL ASPECTS}

Human haptoglobin is a tetramer of two light $\alpha$-chains $(\alpha 1$ or $\alpha 2)$ and two heavy $\beta$-chains linked by disulfide bridges into $\alpha \beta$-dimers, and then into tetramers, and structurally resembles immunoglobulins. Characterization of the haptoglobin cDNA showed that the $\alpha$-chain $(\alpha 1$ or $\alpha 2)$ and the $\beta$-chain are encoded by the $H p$ gene in tandem form, because of which the full-length precursor of haptoglobin (prehaptoglobin, Pre-Hp) is synthesized. According to the UniProt database, there are two isoforms of haptoglobin, or rather Pre-Hp: the canonical isoform 1 (PreHp2), which consists of 406 amino acid residues (a.a.) (Mw 45200), and isoform 2 (Pre-Hp1), which consists of 347 a.a. (Mw 38452) and differs from isoform 1 in absence of the 38-96 amino acid region. (Fig. 2). Inside the full-length polypeptide, the $\alpha$ - and $\beta$-chains are separated by one linker codon corresponding to the $\operatorname{Arg} 84 \alpha 1$-chain and $\operatorname{Arg} 143 \alpha 2$-chain [13]. Only the $\alpha$-chains differ, and the $\beta$-chain (pI 6.32/Mw 27265) is identical in three alleles (245 a.a.) [14]. Alleles $H p 1 S, H p 1 F$ encode polypeptide chains $\alpha 1 \mathrm{~S}$ (slow) and $\alpha 1 \mathrm{~F}$ (fast) (pI 5.23/Mw 9192) of the same length (83 a.a.), but $\alpha 1 \mathrm{~F}$ has aspartic acid and lysine residues at positions 52 and 53, and $\alpha 1 \mathrm{~S}-$ residues of asparagine and glutamic acids in the same positions [6]. In the case of $\alpha 2$, additionally, the same amino acid substitutions are corresponding to positions 111 and 112 [15]. Heterogeneity of the $\alpha$-chains of haptoglobin is detected by the separation of proteins by two-dimensional electrophoresis (2DE) $[15,16]$. The $\alpha 1$ chain has two free SH-groups of Cys residues. One is at the $\mathrm{COOH}$-terminus, Cys72, and always binds to the $\beta$-chain by a disulfide bond, forming a unit ( $\alpha 1 \beta$-dimer). The other, at the $\mathrm{NH}_{2}$-terminus, Cys15, binds to another $(\alpha 1 \beta)$ unit, resulting in the formation of $(\alpha 1 \beta) 2$ or mature Hp1-1, which is a tetramer $[15,16]$. The $H p 2$ allele is a product of partial gene duplication as a result of non-homologous crossing over between $\mathrm{Hp} 1 \mathrm{~S}, \mathrm{Hp} 1 \mathrm{~F}$ alleles and encodes the $\alpha 2$-chain (pI 5.57/Mw 15946) [15]. It contains the same a.a. as $\alpha 1$ and an additional copy of $12-70$ a.a.142 a.a. in total. By binding to the $\beta$-chain, the $\alpha 2$-chain forms $(\alpha 2 \beta)$ unit. Unlike $\alpha 1, \alpha 2$ has three 
(a)

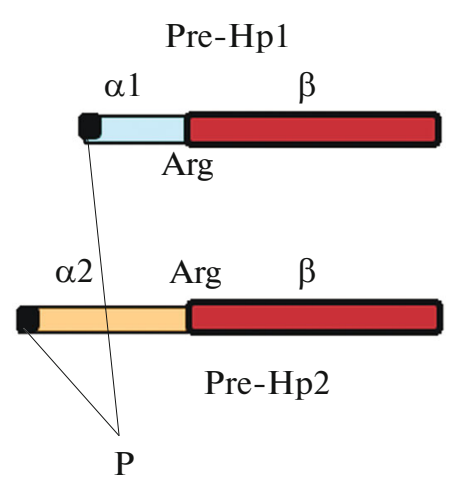

$(\alpha 1 \beta)_{2}$

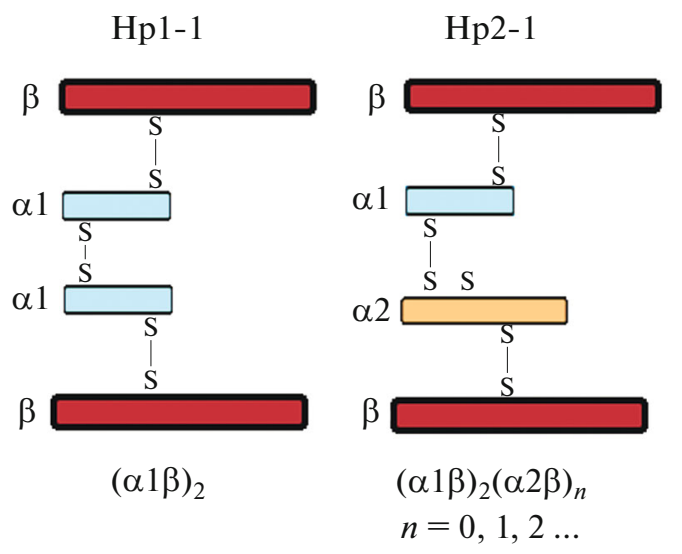

(b)

(c)

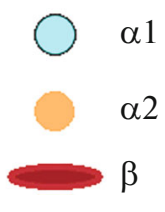

$\alpha 1$
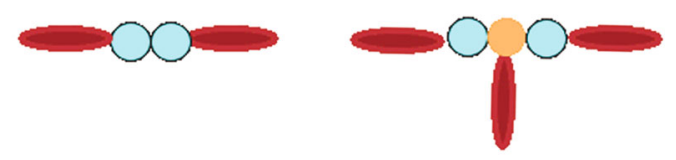
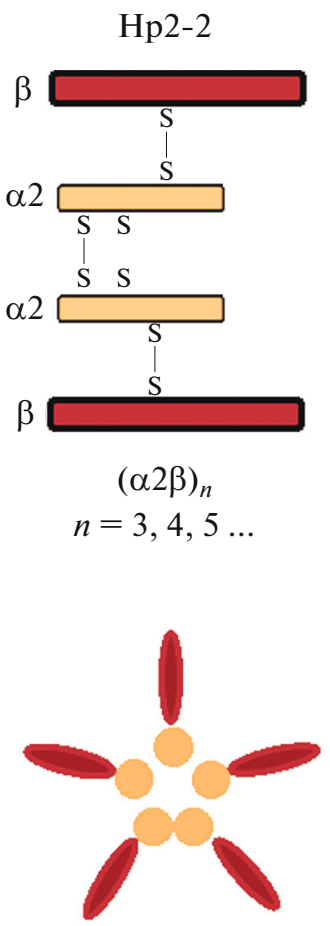

Fig. 2. Diagram of maturation and structure of different types of Hp. (a) Pre-Hp is translated as a single-chain precursor protein; Arg, restricted proteolysis site; P is a signal peptide. (b) Assembly of $\alpha 1 \beta$ and $\alpha 2 \beta$ dimers and $\mathrm{Hp}$ tetramers using disulfide bonds at free Cys (S) residues. (c) Hp1-tetramer, Hp2-1-linear polymer, Hp2-2-ring polymer. Adapted from [30, 48].

free $\mathrm{SH}$-groups of Cys residues, one of them can interact with an additional $\alpha \beta$ unit $(\alpha 1 \beta$ or $\alpha 2 \beta)$, with the formation of large polymers (heterogeneous mixture of multimers) [13, 17, 18]. According to recent genetic analyzes, the larger $\mathrm{Hp} 2$ variant is considered the progenitor of all human $\mathrm{Hp}$ alleles. It follows from this model that exons 3 and 4 of the $\mathrm{Hp} 2$ allele of the progenitor were deleted due to non-allelic homologous recombination during the structural evolution of $\mathrm{Hp} 2$ into $H p 1$ [12, 19-21]. These two exons determine the multimeric structure of Hp2-2 and Hp 2-1 [22]. The Hp0-0 phenotype is characterized by the absence of $\mathrm{Hp}$ or its decreased level in plasma (agaptoglobinemia) and indicates that Hp, surprisingly, is not necessary for the organism's survival. It is assumed that the decrease in the level of $\mathrm{Hp}$ expression is associated with possible mutations [23, 24].

Protein $\mathrm{Hp}$ has a domain structure. Hp variants are largely homologous to MASP, with the $\alpha$-chain containing the complement control protein (CCP) domain, and the $\beta$-chain containing the catalytically inactive chymotrypsin-like serine proteinase (SP) domain [25]. This is an amazing example of homologous proteins with different biological functions. Active sites typical of serine proteases (His57 and Ser195) in $\mathrm{Hp}$ are replaced by lysine and alanine, respectively, which excludes the possibility of Hp protease activity [26].
Many secreted proteins are synthesized as proforms and become biologically active after proteolytic cleavage (processing) in the Golgi apparatus. Hp is unusual in that it is cut in the endoplasmic reticulum before entering the Golgi apparatus [13, 27, 28]. Haptoglobin is transcribed and translated as a single polypeptide, a precursor of either Pre-Hp1 or Pre-Hp2, depending on the genotype/phenotype. During processing, the $\mathrm{N}$-terminal signal peptide is first removed from it, and then it undergoes complex post-translational modifications in the endoplasmic reticulum. At the site of restricted proteolysis (Arg 143 in the case of $\mathrm{Hp} 2$ and Arg84 in the case of Hp1), the polypeptide splits into two subunits: the $\mathrm{N}$-terminal light $\alpha$-chain and the $\mathrm{C}$-terminal heavy $\beta$-chain. The $\mathrm{C}$-terminal Arg of the $\alpha$-chain is removed by carboxypeptidase $N$. Both chains are covalently linked by a disulfide bond, forming the basic $\alpha 1 \beta$ or $\alpha 2 \beta$ unit (dimers) $[19,20]$ (Fig. 2). Interestingly, a variant is possible here when the canonical form encoded by the $\mathrm{Hp} 2-2$ allele does not undergo proteolytic processing, remains fulllength, and functions as a zonulin protein. Proteomic analysis showed that the zonulin protein is identical to Pre-Hp2 [29]. Zonulin is produced in the intestinal mucosa and in the liver, reversibly regulates intestinal permeability, modulating tight junctions between the cells of the digestive tract wall, and controls the balance between tolerance and immunity to foreign anti- 


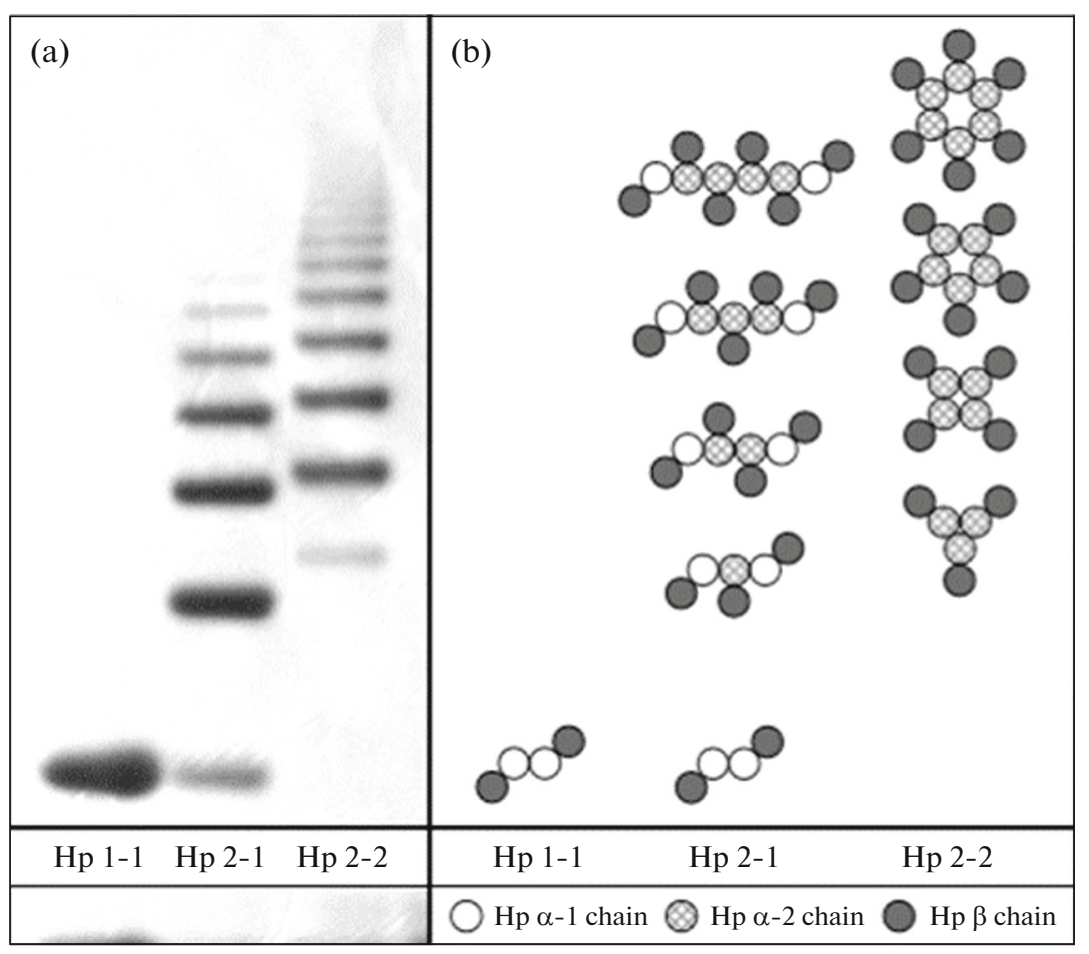

Fig. 3. Assessment of the phenotype of haptoglobin using native PAGE. (a) Specific profiles obtained by electrophoresis in gradient (3-8\%) native PAGE of haptoglobin preparations of various phenotypes. (b) Composition of polymers of three haptoglobin phenotypes: Hp1-1-homodimers; Hp2-1-linear heterodimers; Hp2-2-cyclic heterodimers. Adapted from [31].

gens. Several diseases are associated with an increased level of zonulin: autoimmune, inflammatory, and neoplastic [30] (Fig. 2). Being in the intact full-length form of the precursor protein, zonulin acts to modulate the permeability of the intestinal barrier, while the main function of mature $\mathrm{Hp}$ is to form a stable complex with $\mathrm{Hb}$ and prevent hemoglobin-induced oxidative tissue damage. This is a striking example of the dependence of the function of a protein on its structure. The importance of the $\mathrm{Hp}$ conformation is emphasized by the fact that antibodies to zonulin identify the $\alpha 1$-chain of Hp only under denaturing conditions [30].

Thus, proteins with different structures, molecular weights, and molecular heterogeneity correspond to the three major $\mathrm{Hp}$ phenotypes. According to the results of native electrophoresis, it follows that $\mathrm{Hp} 1-1$ $(\mathrm{Mw} 86000)$ is a tetramer $(\alpha 1 \beta) 2$; Hp2-1 (Mw 86000-300000) and Hp2-2 (Mw 170000900000) are heterogeneous (multimeric) polymer mixtures (Fig. 3). Full forms of haptoglobin of different types consist of $(\alpha \beta)$ units with different numbers of thiol groups in $\alpha$ chains (cysteine residues): in $\alpha 1 \beta$ there are two cysteine residues and in $\alpha 2 \beta$-three. As a result, depending on the phenotype, there are different structures of haptoglobin: $\mathrm{Hp} 1-1-(\alpha 1 \beta) 2$; Hp2-1- $(\alpha 1 \beta) 2(\alpha 2 \beta) n$, where $n=0,1,2,3 \ldots$; Hp2-2- $(\alpha 2 \beta) n$, where $n=3,4,5 \ldots$. Forms with 10 repeating units $(\alpha \beta) 10$ in Hp2-1 and 20 repeating units $(\alpha \beta) 20$ in Hp2-2; Hp1-1 has one form corresponding to the $\alpha \beta$-dimer $[18,31-33]$ (Fig. 3). Besides, it follows from these studies that haptoglobin with the Hp2-1 phenotype is a linear polymer in which $\alpha 1 \beta$ always forms terminal units, and with the $\mathrm{Hp} 2-2$ phenotype, it is a ring polymer, a cyclic structure consisting of many $(\alpha 2 \beta)$ units. These structures of haptoglobin are confirmed using electron microscopy. The functional role of such complex structural HP variants is still unclear [13]. An individual belonging to the Hp polymer phenotype is associated with different levels of the antioxidant function of $\mathrm{Hp}$ and the risk of many common diseases [34-36].

\section{BLOOD PLASMA PROTEINS AND THEIR VARIABILITY}

The functioning of haptoglobin cannot be considered in isolation from the entire plasma, of which it is one of the important components. Plasma proteome is a dynamic, complex mixture of proteins, an important substance for clinical analysis. Proteomic profiles of plasma proteins can illustrate differences associated with metabolic changes or pathological processes since many proteins circulating in the plasma are products of cascades of enzymatic reactions of all tissues and organs and can reflect the physiological state of the body. Systemic proteomic profiling of most of the circulating plasma proteins (plasma proteome) 
makes it possible to detect new biomarkers to predict and diagnose diseases [37]. For example, the use of proteomic approaches to compare proteomes in patients with glioblastoma and healthy donors have shown that some serum proteins associated with different vital physiological pathways, including haptoglobin, are represented in different ways [38].

Analysis of plasma proteins is difficult due to the complexity of the plasma proteome, its dynamism, chemical similarity of many proteins, and a huge range of concentrations of various proteins [39]. Acutephase proteins are common indicators and biomarkers for prognostic and diagnostic assessment of the state of the body. The acute-phase response of homeostasis disturbance produces a cascade of changes in the regulation of transcription, which leads to an increase in the synthesis of some proteins and a decrease in the synthesis of others [40]. Prominent examples of an increased protein response are C-reactive protein, serum amyloid A, and haptoglobin. These proteins are produced in the liver as a result of induction by cytokines during inflammatory processes and are secreted into the plasma [41]. It should also be noted the importance of assessing the variability of the proteomic profile of a potential marker protein in healthy individuals of the control group before carrying out comparative proteomic analyzes to distinguish changes characteristic of any disease from the natural plasticity of the proteome. The variability in the level of some major plasma polypeptides can be comparable or even greater than the difference in levels found in pathology [42]. In the case of haptoglobin, its level is normally in the range of $450 \mathrm{mg} / \mathrm{L}$ to $1650 \mathrm{mg} / \mathrm{L}$. A level below $450 \mathrm{mg} / \mathrm{L}$ may indicate an increased rate of red blood cell death. The increased breakdown of red blood cells leads to an increase in the supply of hemoglobin into the blood and, accordingly, to a decrease in the level of haptoglobin. Therefore, the determination of the content of haptoglobin is used primarily to identify and assess the degree of hemolytic anemia. For individual $\mathrm{Hp}$ chains, the concentration ranges in healthy individuals are as follows: for the $\beta$-chain, $6-$ $40 \mu \mathrm{M}$; for the $\alpha 1$-chain, $0-40 \mu \mathrm{M}$; for the $\alpha 2$-chain, $0-40 \mu \mathrm{M}$ [43].

The complexity of the canonical structure of haptoglobin (homodimers and heterodimers, structured into tetramers); the formation of heterogeneous linear and cyclic polymer structures (polymorphic variants of the $\alpha 1$-chain $(\alpha 1 \mathrm{~F}, \alpha 1 \mathrm{~S})$ [16], proteolytic processing and PTM of $\alpha 1$ - and $\alpha 2$-chains, the presence of four sites of active glycosylation of the $\beta$-chain) indicate that haptoglobin can exist in the form of a variety of proteoforms and to be involved in the performance of various functions [33]. Also, individuals are often burdened with several diseases, each of which can contribute to the change in the level and nature of haptoglobin's PTMs, so it is always necessary to examine a large amount of data to obtain statistically reliable results. From the above, it follows that $\mathrm{Hp}$ is not a very suitable protein as a possible biomarker based on the assessment of changes in the total level of this protein only. However, with the help of modern proteomic technologies, among thousands of protein forms (proteoforms), those that undergo significant modifications in pathology are found, allelic variants and variable PTMs are identified by changes in the fundamental physicochemical characteristics of the protein: molecular weight $(\mathrm{Mw})$ and isoelectric point $(\mathrm{pI})$. An important point here is phenotyping, which is the possibility of a clear definition of the type of $\mathrm{Hp}$ of an individual and the constancy of this characteristic throughout life [33, 35, 44]. Due to this, Hp can be an extremely useful nonspecific polypeptide, a potential marker of many, including malignant neoplasms. Knowledge of the many plasma proteoforms of $\mathrm{Hp}$ can be important for the strategy, diagnosis, treatment, and prevention of various diseases, that is, it has great therapeutic potential.

There is evidence that in some cases the unprocessed Pre-Hp form (Fig. 2) may be a more useful candidate for a biomarker than the mature $\mathrm{Hp}$. For example, in the serum of patients with hepatoma, the Pre-Hp level is much higher than in healthy donors [45].

\section{BASIC FUNCTIONS AND ROLE OF THE Hp PHENOTYPE}

Numerous studies indicate that haptoglobin circulates in the blood plasma as a polymer, whose stoichiometry, size, and biophysical properties depend on three main, hereditarily determined phenotypes (homozygous Hp1-1, Hp2-2, and heterozygous Hp2-1), and are fundamentally different. Moreover, structural differences between phenotypic forms have important functional consequences [46].

The most important function of haptoglobin is the ability to bind free hemoglobin, to be an antioxidant. The $\mathrm{Hp}$ bond with free $\mathrm{Hb}$ (complex) has the highest protein-protein affinity with $K_{\mathrm{d}}=10^{-14} \mathrm{M}$ [47]. This underscores the importance of the biological process under consideration for protecting the body from oxidative damage. It was established by the method of selective proteolysis that only heavy $\beta$-chains of $\mathrm{Hp}$ are involved in binding [48]. Significant negative effects occur within tissues when hemoglobin remains in circulation. Free hemoglobin is highly toxic due to the oxidative nature of heme, which contains iron involved in the production of reactive oxygen molecules that cause cell damage [14, 49]. Moreover, it was found that the ability to reduce the degree of damage caused by free radicals depends on the Hp phenotype [50]. Numerous studies indicate that an individual's belonging to the $\mathrm{Hp}$ polymeric phenotype (Hp2-1 and, especially, $\mathrm{Hp} 2-2$ ) is associated with the risk of many common diseases: cardiovascular, autoimmune, infectious, atherosclerosis, stroke, diabetes, tubercu- 
losis, epilepsy, diabetic nephropathy, diabetic retinopathy, malignant neoplasms, weakening of cognitive functions [33-36, 51-53]. However, in the case of prostate cancer, the role of the phenotype has not been found [54]. An important site of $\mathrm{Hp}$ synthesis, apart from the liver, is the lungs. Haptoglobin protects the lungs from inflammatory agents and prevents lung damage. Its deficiency leads to the destruction of lung tissue caused by the natural bacteriostatic function of neutrophils, which leads to emphysema and chronic obstructive pulmonary disease (COPD). In [10], the Hp2-2 phenotype is considered a new biomarker for COPD identification. The determination of the patient's haptoglobin phenotype may be an important factor in the prognosis of the disease and the course of treatment [35]. Note that in routine laboratory practice for phenotyping $\mathrm{Hp}$, a method based on a PCR reaction taking into account the structural differences of $\mathrm{Hp} 1$ and $\mathrm{Hp} 2$ alleles is successfully used [24]. Another new method of Hp phenotyping using fluorescent probes of gold nanoclusters (AuNC) is described in [55].

A pathological situation affecting the level of Hp in the blood is an acute phase condition, which includes infection, inflammation, tumor, burn, frostbite, chemical damage, autoimmune disease, hemolysis, etc. Here, the main function of $\mathrm{Hp}$ is to bind free hemoglobin released from destroyed red blood cells. Hemoglobin is contained in red blood cells, delivers oxygen to tissues, and participates in the transport of carbon dioxide. The lifetime of an erythrocyte is 120 days. The release of hemoglobin into plasma is a physiological phenomenon associated with intravascular hemolysis due to the destruction of old erythrocytes at a rate of $2 \times 10^{6}$ cells/s [56, 57]. Free $\mathrm{Hb}$ binds to $\mathrm{Hp}$, forming a $\mathrm{Hp} / \mathrm{Hb}$ complex. In the liver, the complex is delivered to the reticuloendothelial system by endocytosis mediated by the CD163 receptor and is degraded. In this way, the loss of free hemoglobin is reduced, iron is recycled (it is returned to the resulting erythrocytes) and the antioxidant function is performed to protect the kidneys from damage by toxic radicals.

In in vitro experiments using mass spectrometry and plasmon resonance, a significant difference in the binding capacity of the two types of haptoglobin, Hp1-1 and Hp2-2, with hemoglobin was not found [58]. When determining the effectiveness of individual phenotype-specific Hp drugs in vivo experiments on guinea pigs with direct infusion, both types of haptoglobin show the same therapeutic efficacy under hemolytic conditions, with hypertension, and effectively prevent the oxidation of LDL (low-density lipoproteins) by hemoglobin. That is, both therapeutic drugs (Hp1-1 and Hp2-2) bind free $\mathrm{Hb}$ equally well with high affinity preventing iron loss and protecting tissues from oxidative effects, even though $\mathrm{Hp} 2-2$ has a heterogeneous multimeric structure compared to dimers Hp1-1. In a review [56], the authors outline possible mechanisms that provide the difference in the functions of $\mathrm{Hp}$ of different types. These studies are important for elucidating the efficacy of Hp preparations of a particular phenotype, and the results presented in the article do not support the concept that phenotype-specific Hp therapists have different efficacy in mitigating hemoglobin toxicity. The authors of the review [56] believe that all three Hp phenotypes have the same binding capacity with $\mathrm{Hb}$, but $\mathrm{Hp} 1-1$ has a greater ability to protect against oxidative damage. It should also be noted that there is a publication indicating that the concentration of Hp1-1 in plasma is higher than the concentration of $\mathrm{Hp} 2-1$ and $\mathrm{Hp} 2-2$ [59]. However, it was shown in [60] that the oxidation of LDL, which plays an important role in atherosclerosis, is practically inhibited by Hp1-1 and only partially by Hp2-2. Further research on this issue appears to be needed. Note that in Japan, Hp preparations under acute hemolytic conditions have been clinically used since 1985 [61].

It was shown that $\mathrm{Hp}$ is an extremely powerful antioxidant that directly protects low-density lipoproteins from $\mathrm{Cu}^{2+}$-induced oxidation [14]. The potential of $\mathrm{Hp}$ is noticeably higher than probucol (one of the most powerful antioxidants). The level of antioxidant activity is distributed in the following order: $\mathrm{Hp} \mathrm{1-1>}$ Hp 2-1 > Hp 2-2 > probucol > vitamin E.

In an in vitro system, on fibroblasts of rabbit arteries, it was shown that $\mathrm{Hp}$ is produced in arterial tissue, where it is involved in cell migration and vascular restructuring [62]. Usually, about $1 \%$ of erythrocytes are destroyed and removed from circulation per day. However, an increase in this amount to at least $2 \%$ leads to the complete disappearance of haptoglobin from the blood [26, 63]. Decreased Hp level is a sign of intravascular hemolysis induced by malaria, poisons, toxins since in the presence of a large amount of free hemoglobin, haptoglobin is depleted [11, 64-66]. However, it is noted that a decrease in the Hp level can also occur in the absence of hemolysis, for example, due to liver cirrhosis, disseminated ovarian carcinomatosis, pulmonary sarcoidosis, or increased estrogen levels [11]. With inflammation, tumor growth, and chemical damage, the level of haptoglobin in the blood rises [41]. Hp has also immunoregulatory properties. It plays a modulating role in the balance of Th1/Th2 helper cells, which are characterized by different patterns of cytokine expression after activation and are responsible for the immune response [67].

To date, fundamentally important results on the role of haptoglobin have been obtained in numerous studies of diabetic patients. First, the incidence of diabetes in individuals with type Hp2-2 haptoglobin is significantly higher than with type Hp1-1 [34, 68]. This disease is characterized by cardiovascular, nervous, and infectious complications. They are largely associated with oxidative stress and antioxidant defenses. Persons with diabetes and with the Hp1-1 
phenotype are resistant to the development of diabetic retinopathy, diabetic nephropathy, and cardiovascular diseases [56]. The authors of the publication [56] believe that the type of $\mathrm{Hp}$ should be considered in diabetic patients as an additional risk factor for cardiovascular diseases. In diabetic patients with $\mathrm{Hp} 2-2$, this risk is five times higher, and with $\mathrm{Hp} 2-1$, it is three times higher than in patients with Hp1-1 [49]. Three possible mechanisms of different $\mathrm{Hp}$ behavior depending on the phenotype are discussed. First, molecular differences in the structure and size of haptoglobin of different types (steric factor) can prevent or exclude the entry of oligomeric molecules of haptoglobin Hp2-1 and Hp2-2 into the intravascular space, where $\mathrm{Hp}$ binds and neutralizes free $\mathrm{Hb}$. As a result, in individuals with the Hp2-1 and Hp2-2 phenotype, free hemoglobin remains circulating for a significant time, contributing to the transition of oxidative stress to vascular stress [49]. Secondly, glycation of hemoglobin is an additional factor that reduces the effectiveness of Hp2-2 as an antioxidant. Diabetes is characterized by the fucosylation of many proteins, including hemoglobin. It was shown that the oxidizing activity of glycated $\mathrm{Hb}$ is not effectively blocked by haptoglobin, and there is a difference in the rate of removal of complexes of glycated $\mathrm{Hb}$ with haptoglobin by hepatocytes as compared to the control [68]. It was found that the risk of coronary heart disease increases in patients with $\mathrm{Hp} 2-2$ when the degree of glycation of hemoglobin is $>6.5 \%$ [69]. That is, a mechanism of significant dysfunction of Hp2-2 with glycated hemoglobin is possible [70]. Third, the presence of the $\mathrm{Hp} 2$ allele in diabetes may be associated with an increase in the amount of active iron [71]. The difference in the binding affinity of $\mathrm{Hp} 1-1$ and $\mathrm{Hp} 2-2$ with hemoglobin has not been detected, but it was found that Hp1-1 and Hp2-2 differ in their ability to prevent the transfer of iron from hemoglobin to the chelated active form. A noticeable increase in the amount of active iron was shown in the case of the $\mathrm{Hp} 2-2 / \mathrm{Hb}$ complexes. In the plasma of genetically modified mice producing Hp2-2, a diabetic-dependent difference in the amount of active iron was also identified. These experimental results indicate that active iron is involved in increasing the susceptibility of individuals with the $\mathrm{Hp} 2$ allele to vascular diseases in diabetic patients, and it follows that, in the context of diabetes, the role of haptoglobin can be both protective and pathogenic.

Iron is one of the most important elements of bacterial growth. The combination of hemorrhagic injury and infection can be fatal due to the presence of blood in the damaged tissue, which provides the necessary iron for the development of microorganisms [72]. However, once bound with haptoglobin, hemoglobin and iron are no longer available to bacteria. Indeed, it has been shown that the negative consequences of intraperitoneal administration of E. coli and hemoglobin to rats can be prevented by the administration of haptoglobin [72]. In the mucous layer and alveolar fluid of the lungs, haptoglobin is the main component of antimicrobial activity and plays an important role in protecting against infection $[44,73]$.

Individuals with type Hp2-2 show high immunological reactivity, including high production of antibodies after vaccination. It was found that $\mathrm{Hp}$ inhibits the synthesis of prostaglandins and thus exhibits antiinflammatory properties $[67,74]$.

Haptoglobin is involved in the inhibition of nitric oxide. Nitric oxide is involved in maintaining vascular tone and is largely depleted by both, hemoglobin and $\mathrm{Hb} / \mathrm{Hp}$ complex, which is undesirable in the case of cardiovascular diseases. The function of inhibition of nitric oxide is better performed in the case of $\mathrm{Hp} 1-1$ since the $\mathrm{Hp} 1-1 / \mathrm{Hb}$ complex is more efficiently removed from the circulation as compared to the Hp2-2/Hb complex [75].

In several works, the angiogenic activity of mature $\mathrm{Hp}$ and Pre-Hp isoforms has been demonstrated. In an in vitro system, it was shown that Pre-Hp enhances the expression of growth factor and receptor (VEGF/VEGFR2), as well as processes and branches in endothelial cells that line the inner surface of blood and lymphatic vessels, that is, stimulates angiogenesis. Moreover, mutant Pre-Hp that cannot turn into $\mathrm{Hp}$ due to a point mutation (replacement of Arg 143 (CGG) with glutamine (CAG) appears to be more effective [45]. In patients with systemic vasculitis, $\mathrm{Hp}$ stimulates tissue repair and compensates for ischemia by promoting the growth of additional vessels. Moreover, Hp2-2 was found to be more angiogenic than other types of $\mathrm{Hp}[34,56,76]$. In an in vitro system, on fibroblasts of rabbit arteries, it was shown that $\mathrm{Hp}$ is expressed in arterial tissue and is involved in cell migration and vascular restructuring [62]. The question of whether Hp belongs to the group of chaperonelike proteins, the so-called extracellular molecular chaperones, capable of stabilizing the conformation of the protein and protecting it from aggregation under stress conditions, is also being investigated. For all types of $\mathrm{Hp}$, prevention of acidic $\left(\mathrm{H}_{2} \mathrm{O}_{2}\right)$ and thermally induced aggregation of catalase and $\gamma$-crystallin (eye lens protein) and only partial refolding of these proteins has been shown [77]. In experiments using fatty acids (oleic, stearic, palmitic), it was shown that the Hp2-2 form prevents the formation of $\beta_{2}$-microglobulin fibrils, which cause inflammation during prolonged dialysis. The formation of amyloid fibrils in such experiments was completely inhibited [2].

It was found that patients with bronchial asthma, which having the Hp2-2 phenotype, are characterized by more pronounced immunological reactivity in comparison with persons with other phenotypes. That is, it can be assumed that the Hp2-2 phenotype is an associated biological marker of bronchial asthma [78]. There is literary evidence that people with the Hp2-2 phenotype are more prone to systemic sclerosis than those with the Hp1-1 phenotype. Moreover, pro- 
teomic analysis indicates an increased level of one of the $\alpha 2$-proteoforms in patients with systemic sclerosis [79].

In the light of recent epidemic events, studies have been conducted to identify the causes of the difference in spread and mortality from COVID-19 in different geographic regions. In particular, this could be associated with a strong geographic variability of plasma protective proteins, including $\mathrm{Hp}[80,81]$. The different phenotypes of haptoglobin did not show a significant correlation with the prevalence of COVID-19 [82]. However, for another protein, ACE1 (angiotensin-converting enzyme 1), a strong correlation was found in its polymorphism, which can be considered as a factor influencing the spread of COVID-19 and the outcome of infection [82].

The haptoglobin-related protein $\mathrm{Hpr}$ is also secreted into plasma, where it is bound to apolipoprotein L-I (apoL-I), which contains high-density lipoprotein (HDL). This complex is called trypanosomal lytic factor-1 (TLF-1) since it provides innate immune protection in humans against many species of African trypanosomes [83]. Also, Hpr, like Hp, can bind hemoglobin with high affinity and assist in the clearance of free hemoglobin to ensure the recirculation of heme iron in the liver. Moreover, in contrast to the $\mathrm{Hp} / \mathrm{Hb}$ complex, the $\mathrm{Hpr} / \mathrm{Hb}$ complex does not have an increased affinity for the CD163 receptor; therefore, the mechanisms of $\mathrm{Hb}$ utilization, in this case, should be different [83].

Despite the weakened functions, the $\mathrm{Hp} 2$ allele dominates in the human population (up to $80 \%$ in some ethnic groups) [18]. There are also reports of the predisposition of persons belonging to the Hp1-1 group to many diseases, in particular to leukemia. So, according to some data, the likelihood of acute lymphocytic leukemia in people with the Hp1-1 group was significantly higher than in people belonging to the Hp2-2 group. The authors believe that the Hp1-1 phenotype can be considered as a sign of an increased risk of chronic lymphocytic leukemia [84]. However, the authors of another study did not find an increase in the frequency of $\mathrm{Hp} 1-1$ representation in patients with chronic lymphocytic leukemia and conclude that in these patients the location of the Hp fractions on the electrophoregram may change and lead to errors when considering the Hp groups [85].

\section{HAPTOGLOBIN AND ITS PROTEOFORMS AS POTENTIAL BIOMARKERS OF DISEASES}

A wide variety of $\mathrm{Hp}$ proteoforms arises due to processing and PTMs. Especially many additional protein variants are formed during glycosylation of the $\beta$-chain of haptoglobin at four Asn sites (Asn 184, Asn207, Asn211, Asn241) [32, 86]. Numerous studies have shown that changes in the modified oligosaccharides of the $\beta$-chain of $\mathrm{Hp}$ in serum/plasma occur in various pathologies, including malignant neoplasms. This makes $\mathrm{Hp}$ (along with other glycan markers) a promising, non-invasive biomarker for diagnosing, predicting, and monitoring patient treatment.

Many studies focus on the identification of PTMs and changes in the level of the $\mathrm{Hp} \alpha 2$-chain in pathology $[15,39,87]$. These characteristics of $\mathrm{Hp}$ indicate the possibility of this protein existing in the form of various proteoforms. Their identification is important for understanding the physiological and pathological role of $\mathrm{Hp}$.

Proteomic technologies are widely used to study PTMs in blood plasma in the case of various diseases. The main research methods for the identification and visualization of proteins are one-dimensional denaturing sodium dodecyl sulfate electrophoresis (SDSPAGE) and two-dimensional electrophoresis (2DE) in combination with Western blotting or mass spectrometry (MS). Such experiments aim to obtain a protein profile (pattern) representing a combination of various proteoforms (Fig. 4). Comparison of 2DEimmunoblots of protein in normal and pathological conditions can give a picture of changes in such parameters as the number of proteoforms (protein spots), their intensity, size, and position. And with the help of MS, numerous site-specific modifications are identified. As for haptoglobin, according to the PhosphoSitePlus information resource, there are 5 serine and tyrosine phosphorylation sites, 5 lysine acetylation sites, and one lysine ubiquitination site of the human $\mathrm{Hp}$ (phosphosite.org). The characteristic protein profile of the $\alpha 2$-chain of $\mathrm{Hp}$ in 2DE-gels upon Coomassie staining is three spots with practically identical coordinates by weight, but different in pI (Fig. 4). The central major spot most likely corresponds to the unmodified form, which has the amino acid sequence shown in the Uniprot database as P00738; one spot migrates to a more acidic $\mathrm{pH}$ range (deamidation of Asn residues at position 5 to aspartic acid); the other spot is displaced to the alkaline side due to the presence of an additional C-terminal residue Arg (basic amino acid), a linker between the $\alpha$ and $\beta$-chains. This information on PTMs of Hp was obtained using the MS and published in [15]. In [39], a change in the profile of these proteoforms in plasma during pregnancy with fetal growth restriction (FGR) was found. These three forms of $\alpha 2-\mathrm{Hp}$ showed different patterns in FGR patients and healthy individuals, and the presence of a specific $\alpha 2-\mathrm{Hp}$ variant unique to FGR patients was found. That is, haptoglobin is a potential marker of this pathology, the prevalence of which is $3 \%$ and poses a significant threat to the health of patients. Also, a change in the protein profile and a significant decrease in the level of $\beta$ - and $\alpha$-chains of $\mathrm{Hp}$ in the plasma of patients with malaria compared with healthy donors have been shown [89]. According to available data [90], phosphorylated and glycosylated proteoforms of the haptoglobin $\alpha 2$-chain are 


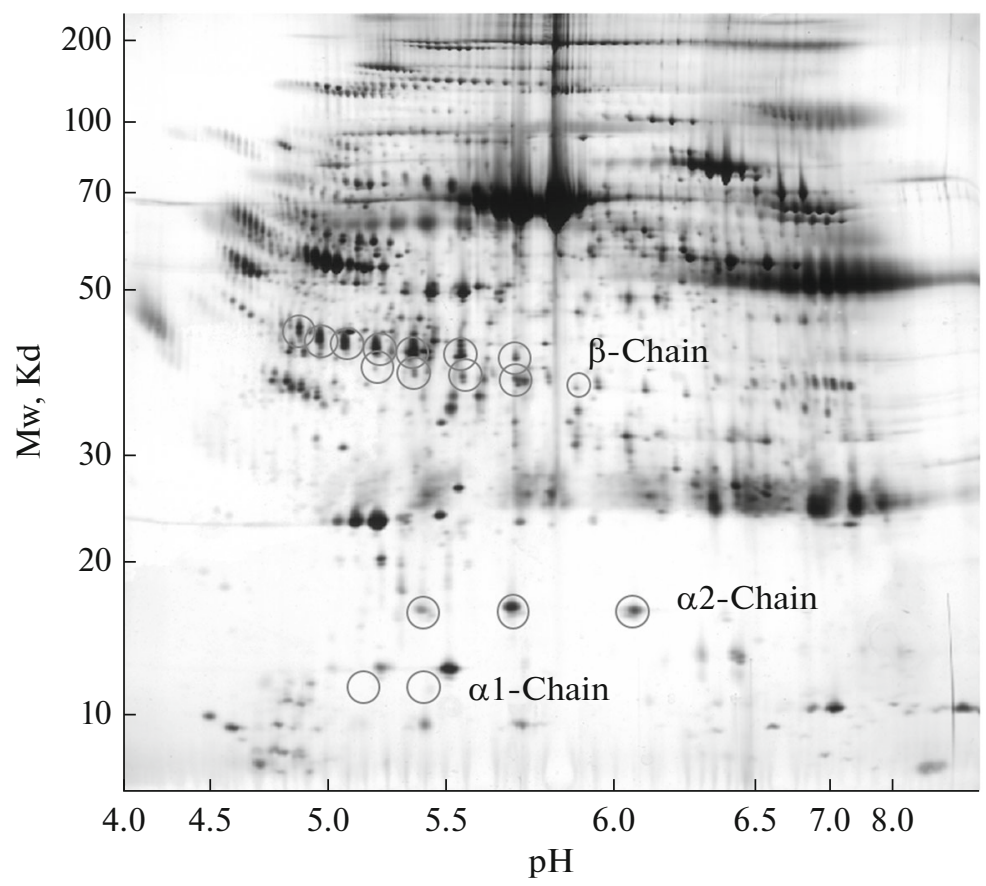

Fig. 4. The 2D electrophoretic map of human plasma proteins. The circles indicate the position of the haptoglobin proteoforms. Adapted from [88].

detected in the plasma of patients with Non-Small Cell Lung Cancer.

Interesting results were obtained, when analyzing the sera of patients with squamous cell lung cancer [91]. 2DE showed an increased level of $\beta$-chain proteoforms. Moreover, in MS analysis, two peptides of these proteoforms were especially pronounced. These data were also supported immunologically. The authors of the publication [91] believe that the detection of one of these peptides (peptide HP216) is a promising biomarker for the early detection of squamous cell carcinoma, especially in combination with the determination of soluble fragments of cytokeratin 19 (CYFRA 21-1), used for diagnosis, prognosis, and control treatment of lung cancer, as well as some other malignant neoplasms [91, 92].

In patients with ovarian cancer, a significant increase in the level of $\mathrm{Hp}$ in plasma was found in comparison with the control, and haptoglobin was recognized as an independent prognostic marker of this disease [93]. Moreover, the increased amount of fucosylated forms of the $\alpha$-chain of haptoglobin in ascitic fluids and tumor tissues of patients with ovarian cancer confirms their potential as biomarkers of disease progression [94, 95].

In the case of breast cancer, it has been shown that the level of $\mathrm{Hp}$ is increased not only in the blood but also in tumor tissues. Moreover, it was unexpectedly found that there is a functional relationship between $\mathrm{Hp}$ and glycolytic enzymes, such as glucose-6-phosphate isomerase and hexokinase [96]. Another disease recently found to have elevated plasma $\mathrm{Hp}$ levels is acute myocardial infarction in young adults [97].

It should also be noted that it is possible to use not only plasma but also saliva for the detection of tumor markers [98], including haptoglobin [99]. For example, comparative proteomic analysis revealed a significant excess (2.5 times) of the level of haptoglobin in saliva in patients with kidney cancer compared with healthy donors [99]. The authors of this study conclude that their experimental results indicate the possibility of using haptoglobin along with the S100A9 protein as potential non-invasive biomarkers for the diagnosis of kidney cancer.

Interesting results were obtained when studying the possible relationship between the $\mathrm{Hp}$ level and liver metastases in colorectal cancer [100]. In this work, the authors showed that knockdown of the $H p$ gene by specific RNAs significantly inhibited tumor growth and invasive properties. The authors believe that an increased level of $\mathrm{Hp}$ can be considered in this case as a predictive marker of liver metastases [100].

In the study of plasma of patients with glioblastoma, an increase in the level and change in the protein profile of the $\alpha 2$-chain of haptoglobin was found. Three $\alpha 2$-proteoforms were identified in the control and six $\alpha 2$-proteoforms in patients. That is, the identification of specific forms of $\alpha 2-\mathrm{Hp}$ in blood plasma can be a biomarker of glioblastoma [38, 101] (Fig. 5). In our studies, this conclusion is also confirmed. Thus, according to our unpublished data, the level of the $\alpha 2$-chain of haptoglobin in the blood plasma of 
patients with glioblastoma is significantly increased in comparison with the plasma of healthy donors. Moreover, comparative analysis of 2DE-profiles revealed variability in the sets of proteoforms (patterns) of the $\alpha 2$-chain of haptoglobin in patients with glioblastoma. Taking into account the results obtained in [102], it can be assumed that the proteoforms of the $\mathrm{Hp}$ $\alpha 2$-chain with a shift of the $\mathrm{pI}$ to the acidic region may not only be deamidated, but also acetylated, and could be potential markers of glioblastoma. Glycosylation is one of the most common and important PTMs that create numerous protein variants due to oligosaccharide heterogeneity, which affects the physical (solubility, stability), structural (folding), and functional properties of proteins $[32,86]$. Changes in glycosylation, minor and significant, are associated with many diseases. Moreover, most of the plasma proteins are glycosylated. Numerous studies show that a comparative analysis of $\mathrm{N}$-glycan profiles using mass spectrometry can allow early diagnosis of different types of malignant neoplasms since certain oligosaccharide structures dominate in different types of this pathology and can be used as biomarkers [103, 104]. Glycan analysis is a study of the oligosaccharide portion of glycoproteins and may include analysis of the whole glycoprotein; separation and detection of glycoforms; analysis of glycopeptides obtained after enzymatic treatment of the glycoprotein; analysis of cleaved glycans obtained after chemical or enzymatic processing of a glycoprotein. The most characteristic violation of glycosylation in comparison with the norm is the degree of branching of N-glycan chains: bi-, tri-, and tetra-antenna structures. They also differ in the number of glycosylation sites and the degree of fucosylation and sialylation [32]. The tri- and tetra-antenna variants are called Lewis Y-tipe structures. The concept of protein and site-specific microheterogeneity is introduced, which controls the structure, function, and interaction of proteins [86, 105]. Most types of malignant neoplasms are characterized by an increase in the level of haptoglobin [106]. In work [107], using 2DE and MS, it was shown a significant increase in the level of modified forms of Pre-Hp in the serum of patients with breast cancer, compared with healthy donors.

It is known that the normal liver fucosyltransferase activity is low, and most of the haptoglobin in healthy individuals is not fucosylated [108]. Studies have shown that changes in the structure of serum (plasma) blood glycans, including haptoglobin, that is, aberrant glycosylation, are often found in connection with cancer, for example, ovarian cancer [94], rectal cancer [106], cancer liver [32, 86, 104], lung cancer [109], pancreatic cancer [108], and stomach cancer [110, 111]. In the plasma of patients with pancreatic cancer, studies have shown an increase in di-, tri-, and tetrabranched glycans, and the number of triantennal glycans containing $\mathrm{X}$-type Lewis fucose markedly increased in the Asn211 site of the Hp $\beta$-chain [108]. High levels of fucosylated $\mathrm{Hp}$ have also been found in the plasma of patients with various carcinomas [112]. An analysis of glycopeptides and cleaved permethylated N-glycans was performed in [86]. Site-specific glycoforms of haptoglobin were found with an increase in $\beta$-chain fucosylation up to six fucoses in liver diseases (cirrhosis and hepatocarcinoma). The authors believe that the observed changes are large enough and specific enough to be a diagnostic test for non-invasive monitoring of the course of the disease. In work [111], the analysis of aberrant glycosylation of $\mathrm{Hp}$ in blood serum in patients with gastric cancer was successfully carried out. The study [104] presents a highly sensitive and specific model for the diagnosis of hepatocarcinoma, which consists of a systemic analysis of serum $\mathrm{Hp}$ concentration and a comparative quantitative analysis of sialylated and fucosylated forms of haptoglobin at different stages of hepatitis and hepatocarcinoma. Using lectin-affinity purification (using glycosyl-specific lectins) and 2DE, 18 variants of S-Hp and F-Hp glycoforms were detected. Using MS, unique patterns of $\mathrm{Hp}$ glycoforms were found in HCC patients, consisting of hypersialated fucosylated and hyposialated fucosylated proteoforms. In special cases, the binding of fucose to the core $\mathrm{N}$-acetylglucosamine residue and the formation of tetraantennal $\beta$-chains have been shown. An increase in the level of fucosylated haptoglobin was found in a comparative analysis of the plasma of patients with psoriasis and healthy individuals. Aberrant glycoforms can reflect changes in $\mathrm{Hp}$ function in the skin and be used as a marker of the disease [113]. A significantly increased level of fucosylated $\mathrm{Hp}(\mathrm{F}-\mathrm{Hp})$ in the serum of patients with pancreatic cancer was also shown, and even monoclonal antibodies highly specific to the form of $\mathrm{F}-\mathrm{Hp}$ present in the patient were obtained $[114,115]$.

A detailed characterization of $\mathrm{Hp}$ glycosylation in different types of malignant neoplasms with a description of the methodological techniques used is given in the review [116]. Important results were obtained in the study of glycosylation of haptoglobin in connection with the affinity of its binding to hemoglobin. Using haptoglobin Hp1-1 as an example, it was shown that fucosylation significantly stabilizes the $\mathrm{Hp} / \mathrm{Hb}$ complexes, and the (branched) antenna structures reduce the binding affinity of such complexes [105]. A large contribution is made by the data presented in [117]. Using native PAGE, gel filtration, ion-exchange chromatography, and advanced MS technologies, the authors have identified hundreds of haptoglobin proteoforms/glycoforms and their combinations. It is shown in detail how they coexist in blood serum, how they differ in individuals with different genotypes (Hp2-1 and Hp2-2) and different oligomeric states of the protein. The authors observed a correlation between the level of glycosylation and the size of the $\mathrm{Hp}$ oligomer. It is noteworthy that the level of fucosylation and branching of glycans decreases with an increase in the size of both Hp2-1 and Hp2-2 oligo- 


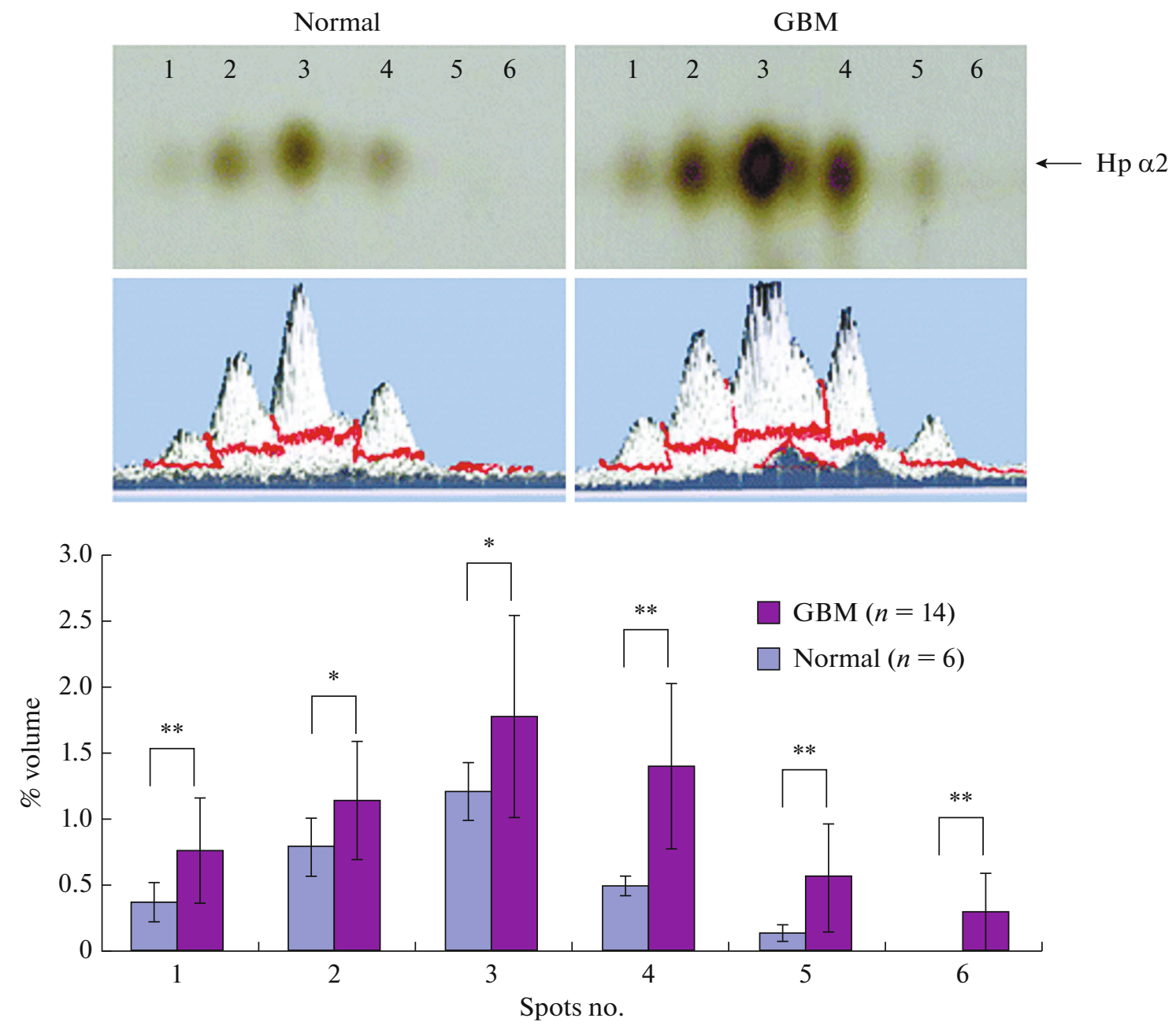

Fig. 5. Proteomic analysis of serum from healthy subjects and patients with glioblastoma (GBM). (Top) Serum proteins from healthy donors and GBM patients were separated by 2DE and visualized by silver staining. (1-6) Spots of the $\alpha 2-\mathrm{Hp}$ chain with the same mass and different pI. (Bottom) Statistical analysis of spot size based on 6 (normal) and 14 (GBM) gels. Taken from [101] with permission from the American Chemical Society.

mers. According to the authors of the publication [117], oligomers with a lower mass have a higher affinity for $\mathrm{Hb}$ compared to oligomers with a larger mass. It is concluded that both significant fucosylation and branching of glycan structures enhance the $\mathrm{Hp}-\mathrm{Hb}$ bond of the complex. Interestingly, it was shown in [105] that Hp1-1 with a higher degree of branching, on the contrary, showed a lower binding affinity with $\mathrm{Hb}$. Also, the effect on the bond in the proteolytic processing complex of the Hp $\alpha$-chain was found: the larger the oligomer, the higher the level of $H p \alpha R$ isoforms ( $\mathrm{R}$ is the $\mathrm{C}$-terminal residue of arginine, the linker between the $\alpha$ - and $\beta$-chains). Removal of C-terminal arginine is considered as the process of $\mathrm{Hp}$ maturation [15]. It was found that, in healthy individuals, the glycosylation sites Asn184, Asn207, Asn241 have preferentially sialylated biantennal N-glycans, while the Asn211 site is occupied by sialylated triantennal N-glycans. Thus, the fine-tuning of the $\mathrm{Hp} / \mathrm{Hb}$ complex formation is influenced by the cumulative effect of many factors, including the haptoglobin genotype, heterogeneous glycosylation patterns, and post-translational proteolytic processing of the haptoglobin $\alpha$-chain. It should be noted that both groups of authors, [105] and [117], used proprietary hemoglobin and haptoglobin preparations. It is obvious that the study of the glycosylation of proteins, including haptoglobin, has become one of the main directions in the research of malignant neoplasms. Glycoproteomics is a technological breakthrough that has begun to show promising results in the identification of biomarkers for early diagnosis and therapy. According to a review [118], there is growing recognition of the enormous potential of glycans for personalized medicine. However, it should be borne in mind that malignant transformation is a heterogeneous disease, and a panel of markers can provide more accurate information than a single marker [109]. 


\section{CONCLUSIONS}

Thus, the level of $\mathrm{Hp}$ in blood plasma can be used not only as a biochemical indicator for diagnosing the development of hemolytic and inflammatory processes in the body and the functional state of the liver. Also, by the phenotype of $\mathrm{Hp}$, one can judge the individual predisposition of a person to various diseases. Therefore, along with the blood group and $\mathrm{Rh}$ factor, the phenotype of $\mathrm{Hp}$ is an important individual trait. When developing, introducing methods of personalized medicine and the appearance of health passports in the future, the Hp phenotype will certainly need to be taken into account. Moreover, there are grounds for the possibility of using Pre-Hp2 (zonulin), as well as proteoforms of both $\alpha$-chains and $\beta$-chains of haptoglobin, as biomarkers of many, including oncological, pathologies.

\section{FUNDING}

The study was carried out within the framework of the State Assignment of the National Research Center Kurchatov Institute-PNPI for 2021-2023.

\section{COMPLIANCE WITH ETHICAL STANDARDS}

All authors declare no potential conflicts of interest warranting disclosure in this article. This article does not contain any research involving humans or the use of animals as objects.

\section{ADDITIONAL INFORMATION} zhny).

The article was translated by the author (S.N. Nary-

\section{REFERENCES}

1. Polonovski, M.J.M., C. R. Seances Soc. Biol. Fil., 1938, vol. 129, pp. 457-460.

2. Sultan, A., Raman, B., Rao, C.M., and Tangirala, R., J. Biol. Chem., 2013, vol. 288, no. 45, pp. 32326-32342.

3. van der Straten, A., Herzog, A., Cabezon, T., and Bollen, A., FEBS Lett., 1984, vol. 168, no. 1, pp. 103-107.

4. Maeda, N. and Smithies, O., Annu. Rev. Genet., 1986, vol. 20, pp. 81-108.

5. Bensi, G., Raugei, G., Klefenz, H., and Cortese, R., EMBO J., 1985, vol. 4, no. 1, pp. 119-126.

6. Smithies, O., Connell, G.E., and Dixon, G.H., Nature, 1962, vol. 196, pp. 232-236.

7. Carter, K. and Worwood, M., Int. J. Lab. Hematol., 2007, vol. 29, no. 2, pp. 92-110.

8. Belov, A.P. and Budjakov, J.S., Sudebno-medicinskay ekspertiza, 1963, vol. 1, pp. 28-29.

9. McEvoy, S.M. and Maeda, N., J. Biol. Chem., 1988, vol. 263, no. 30, pp. 15740-15743.

10. Lee, P.L., Lee, K.Y., Cheng, T.M., Chuang, H.C., Wu, S.M., Feng, P.H., Liu, W.T., Chen, K.Y., and Ho, S.C., Sci. Rep., 2019, vol. 9, no. 1, pp. 1-8.
11. Shih, A.W.Y., Mcfarlane, A., and Verhovsek, M., Am. J. Hematol., 2014, vol. 89, no. 4, pp. 443-447.

12. Wicher, K.B. and Fries, E., J. Mol. Evol., 2007, vol. 65, no. 4, pp. 373-379.

13. Schaer, C.A., Owczarek, C., Deuel, J.W., Schauer, S., Baek, J.H., Yalamanoglu, A., Hardy, M.P., Scotney, P.D., Schmidt, P.M., Pelzing, M., Soupourmas, P., Buehler, P.W., and Schaer, D.J., BMC Biotechnol., 2018, vol. 18, no. 1, 15. https://doi.org/10.1186/s12896-018-0424-3

14. Tseng, C.F., Lin, C.C., Huang, H.Y., Liu, H.C., and Mao, S.J.T., Proteomics, 2004, vol. 4, no. 8, pp. 22212228.

15. Mikkat, S., Koy, C., Ulbrich, M., Ringel, B., and Glocker, M.O., Proteomics, 2004, vol. 4, no. 12, pp. 3921-3932.

16. John, H.A. and Purdom, I.F., Genet. Res., 1987, vol. 50, no. 1, pp. 17-21.

17. Polticelli, F., Bocedi, A., Minervini, G., and Ascenzi, P., FEBS J., 2008, vol. 275, no. 22, pp. 56485656.

18. Larsson, M., Cheng, T.-M., Chen, C.-Y., and Mao, S.J.T., in Unique Assembly Structure of Human Haptoglobin Phenotypes 1-1, 2-1, and 2-2 and a Predominant Hp 1 Allele Hypothesis. Acute Phase Proteins, INTECH 2013, Chapter 7, pp. 163-179.

19. Yang, F., Brune, J.L., Baldwin, W.D., Barnett, D.R., and Bowman, B.H., Proc. Natl. Acad. Sci. USA, 1983, vol. 80, no. 19, pp. 5875-5879.

20. Wicher, K.B. and Fries, E., Proc. Natl. Acad. Sci. USA, 2004, vol. 101, no. 40, pp. 14390-14395.

21. Buehler, P.W., Humar, R., and Schaer, D.J., Trends Mol. Med., 2020, vol. 26, no. 7, pp. 683-697.

22. Boettger, L.M., Salem, R.M., Robert, E., Handsaker, R.E., Peloso, G., Kathiresan, S., Hirschhorn, J., and McCarroll, S.A., Nat. Genet., 2016, vol. 48, vol. 4, pp. 359-366.

23. Koda, Y., Soejima, M., Yoshioka, N., and Kimura, H., Am. J. Hum. Genet, 1998, vol. 62, no. 2, pp. 245-252.

24. Park, K.U., Song, J., and Kim, J.Q., J. Clin. Pathol., 2004, vol. 57, no. 10, pp. 1094-1095.

25. Kurosky, A., Barnett, D.R., Lee, T.-H, Touchstone, B., Hay, R.E., Arnott, M.S., Bowman, B.H., and Fitch, A.W., Proc. Natl. Acad. Sci. USA, 1980, vol. 77, no. 6, pp. 3388-3392.

26. Alayash, A.I., Andersen, C.B.F., Moestrup, S.K., and Bülow, L., Trends Biotechnol., 2013, vol. 31, no. 1, pp. 2-3.

27. Wassler, M. and Fries, E., J. Cell Biol., 1993, vol. 123, no. 2, pp. 285-291.

28. Hanley, J.M., Haugen, T.H., and Heath, E.C., J. Biol. Chem., 1983, vol. 258, no. 12, pp. 7858-7869.

29. Tripathi, A., Lammers, K.M., Goldblum, S., SheaDonohue, T., Netzel-Arnettb, S., Buzza, M.S., Antalis, T.M., Vogel, S.N., Zhao, A., Yang, S., Arriettac, M.-C., Meddingsd, J.B., and Fasano, A., Proc. Natl. Acad. Sci. USA, 2009, vol. 106, no. 39, pp. 16799-16704.

30. Fasano, A., Physiol. Rev., 2011, vol. 91, no. 1, pp. 151175. 
31. Gast, M.C.W., van Tinteren, H., Bontenbal, M., van Hoesel, R.Q.G.C.M., Nooij, M.A., Rodenhuis, S., Span, P.N., Tjan-Heijnen, V. CG., de Vries, E. GE., Harris, N., Twisk, J.WR., Schellens, J. H.M., and Beijnen, J.H., BMC Cancer, 2008, vol. 8, 389.

https://doi.org/10.1186/1471-2407-8-389

32. Clerc, F., Reiding, K.R., Jansen, B.C., Kammeijer, G.S.M., Bondt, A., and Wuhrer, M., Glycoconj. J., 2016, vol. 33, no. 3, pp. 309-343.

33. Beeri, M.S., Lin, H.M., Sano, M., RavonaSpringer, R., Liu, X., Bendlin, B.B., Gleason, C.E., Guerrero-Berroa, E., Soleimani, L., Launer, L.J., Ehrenberg, S., Lache, O., Seligman, Y.K., and Levy, A.P., JAMA Netw. Open, 2018, vol. 1, no. 7, e184458. https://doi.org/10.1001/jamanetworkopen.2018.4458

34. Wobeto, V.P. de A., Zaccariotto, T.R., and Sonati, M. de F., Genet. Mol. Biol., 2008, vol. 31, no. 3, pp. 602620 .

35. Ko, D.H., Chang, H.E., Kim, T.S., Song, E.Y., Park, K.U., Song, J., and Han, K.S., Biomed. Res. Int., 2013, vol. 2013, 390630.

https://doi.org/10.1155/2013/390630

36. Simpson, M., Snell-Bergeon, J.K., Kinney, G.L., Lache, O., Miller-Lotan, R., Anbinder, Y., Rewers, M.J., and Levy, A.P., Cardiovasc. Diabetol., 2011, vol. 10, 99 . https://doi.org/10.1186/1475-2840-10-99

37. Smith, J.G. and Gerszten, R.E., Circulation, 2017, vol. 135, vol. 17, pp. 1651-1664.

38. Gollapalli, K., Ray, S., Srivastava, R., Renu, D., Singh, P., Dhali, S., Dikshit, J.B., Srikanth, R., Moiyadi, A., and Srivastava, S., Proteomics, 2012, vol. 12, no. 14 , pp. $2378-2390$.

39. Gupta, M.B., Seferovic, M.D., Liu, S., Gratton, R.J. Doherty-Kirby, A., Lajoie, G.A., and Han, V.K.M., Clinical Proteomics, 2006, vol. 2, pp. 169-184.

40. Nirala, N.R. and Shtenberg, G., Biomolecules, 2019, vol. 9, pp. 12-19.

41. Raynes, J.G., Eagling, S., and Mcadam, K.P.W.J., Clin. Exp. Immunol., 1991, vol. 83, no. 3, pp. 488-491.

42. Pakharukov, N.A., Pastushkova, L.K., Moshkovskii, S.A., and Larina, I.M., Biochem. Suppl. Ser. B Biomed. Chem., 2011, vol. 5, no. 3, pp. 203-212.

43. Hortin, G., Sviridov, D., and Anderson, N.L., Clin. Chem., 2008, vol. 54, no. 10, pp. 1608-1616.

44. Sadrzadeh, S.M.H. and Bozorgmehr, J., J. Clin. Pathol., 2004, vol. 121, suppl., pp. S97-104.

45. Oh, M.K., Park, H.J., Lee, J.H., Bae, H.M., and Kim, I.S., FEBS Lett., 2015, vol. 589, no. 9, pp. 10091017.

46. Di Masi, A, De Simone, G., Ciaccio, C., D’Orso, S., Coletta, M., and Ascenzi, P., Mol. Aspects Med., 2020, vol. 73, 100851.

https://doi.org/10.1016/j.mam.2020.100851

47. McCormick, D.J. and Atassi, M.Z., J. Protein Chem., 1990, vol. 9, no. 6, pp. 735-742.

48. Lustbader, J.W., Arcoleo, J.P., Birken, S., and Greer, J., J. Biol. Chem., 1983, vol. 258, no. 2, pp. 1227-1234.
49. Bale, B.F., Doneen, A.L., and Vigerust, D.J., Front. Cardiovasc. Med., 2018, vol. 5, 141.

https://doi.org/10.3389/fcvm.2019.00194

50. Melamed-Frank, M., Lache, O., Enav, B.I., Szafranek, T., Levy, N.S., Ricklis, R.M., and Levy, A.P., Blood, 2001, vol. 8, no. 13, pp. 3693-3698.

51. Goldenstein, H., Levy, N.S., and Levy, A.P., Pharmacol. Res., 2012, vol. 66, no. 1, pp. 1-6.

52. Levy, A.P., Hochberg, I., Jablonski, K., Resnick, H.E., Lee, E.T., Best, L., and Howard, B.V., J. Am. Coll. Cardiol., 2002, vol. 40, no. 11, pp. 1984-1990.

53. Aghaalikhani, N., Zamani, M., Allameh, A., Mashayekhi, A., Shadpour, P., Mahmoodi, M., and Rashtchizadeh, N., EXCLI J., 2020, vol. 19, pp. 351359.

54. Kaiser, M., Thurner, EM., Mangge, H., et al., Sci. Rep., 2020, vol. 10, 13117. https://doi.org/10.1038/s41598-020-69333-z

55. Tan, S.H., Yougbaré, S., Chu, HL., Kuo, T.R., and Cheng, T.M., Polymers (Basel), 2020, vol. 12, no. 1, 2242. PMID: PMCID: PMC7601242. https://doi.org/10.3390/polym 12102242

56. MacKellar, M. and Vigerust, D.J., Clin. Diabetes, 2016, vol. 34, no. 3, pp. 148-157.

57. Ascenzi, P., Bocedi, A., Visca, P., Altruda, F., Tolosano, E., Beringhelli, T., and Fasano, M., IUBMB Life, 2005, vol. 57, no. 11, pp. 749-759.

58. Lipiski, M., Deuel, J.W., Baek, J.H., Engelsberger, W.R., Buehler, P.W., and Schaer, D.J., Antioxidants Redox Signal., 2013, vol. 19, no. 14, pp. 1619-1633.

59. Cheng, T.M., Pan, J.P., Lai, S.T., Kao, L.P., Lin, H.H., and Mao, S.J.T., Clin. Biochem., 2007, vol. 40, nos. 13-14, pp. 1045-1056.

60. Bamm, V. V., Tsemakhovich, V.A., Shaklai, M., and Shaklai, N., Biochemistry, 2004, vol. 43, no. 13, pp. 3899-3906.

61. Schaer, D.J., Buehler, P.W., Alayash, A.I., Belcher, J.D., and Vercellotti, G.M., Blood, 2013, vol. 121, no. 8, pp. 1276-1284.

62. de Kleijn, D.P.V., Smeets, M.B., Kemmeren, P.P.C.W., Lim, S.K., van Middelaar, B.J., Velema, E., Schoneveld, A., Pasterkamp, G., and Borst, C., FASEB J., 2002, vol. 16, no. 9, pp. 1123-1125.

63. Nantasenamat, C., Prachayasittikul, V., and Bulow, L., PLoS One, 2013, vol. 8, no. 4, e62996. https://doi.org/10.1371/journal.pone.0062996

64. Lim, S.K., Redox Rep., 2001, vol. 6, no. 6, pp. 375-378.

65. Nielsen, M.J. and Moestrup, S.K., Blood, 2009, vol. 108, no. 8, pp. 2846-2849.

66. Tolosano, E., Fagoonee, S., Hirsch, E., Berger, F.G., Baumann, H., Silengo, L., and Altruda, F., Blood, 2002, vol. 100, no. 12, pp. 4201-4205.

67. Arredouani, M., Matthijs, P., Van Hoeyveld, E., Kasran, A., Baumann, H., Ceuppens, J.L., and Stevens E., Immunology, 2003, vol. 108, pp. 144-151.

68. Asleh, R., Marsh, S., Shilkrut, M., Binah, O., Guetta, J., Lejbkowicz, F., Enav, B., Shehadeh, N., Kanter, Y., Lache, O., Cohen, O., Levy, N.S., and Levy, A.P., Circ. Res., 2003, vol. 92, pp. 1193-1200.

69. Cahill, L.E., Jensen, M.K., Chiuve, S.E., Shalom, H., Pai, J.K., Flint, A.J., Mukamal, K.J., Rexrode, K.M., 
Levy, A.P., and Rimm, E.B., J. Am. Coll. Cardiol., 2015, vol. 66, no. 16, pp. 1791-1799.

70. Cahill, L.E., Levy, A.P., Chiuve, S.E., Jensen, M.K., Wang, H., Shara, N.M., Blum, S., Howard, B.V., Pa, J.K., Mukamal, K.J., Rexrode, K.M., and Rimm, E.B., J. Am. Coll. Cardiol., 2013, vol. 61, no. 7, pp. 728-737.

71. Asleh, R., Guetta, J., Kalet-Litman, S., MillerLotan, R., and Levy, A.P., Circ. Res., 2005, vol. 96, vol. 435-441.

72. Eaton, J.W., Brandt, P., Mahoney, J.R., and Lee, J.T., Science, 1982, vol. 215, pp. 691-693.

73. Yang, F., Friedrichs, W.E., Navarijo-Ashbaugh, A.L., DeGraffenried, L.A., Bowman, B.H., and Coalson, J.J., Lab. Investig., 1995, vol. 73, no. 3, pp. 433-440.

74. Langlois, M.R. and Delanghe, J.R., Clin. Chem., 1996, vol. 42, no. 10, pp. 1589-1600.

75. Sertório, J.T., Lacchini, R., Amaral, L.M., Palei, A.C.T., Cavalli, R.C., Sandrim, V.C., Duarte, G., and Tanus-Santos, J.E., J. Hum. Hypertens, 2013, vol. 27, pp. 349-354.

76. Cid, M.C., Grant, D.S., Hoffman, G.S., Auerbach, R., Fauci, A.S., and Kleinman, H.K., J. Clin. Invest., 1993, vol. 91, pp. 977-985.

77. Pavlíček, Z. and Ettrich, R., Collect. Czechoslov. Chem. Commun., 1999, vol. 4, pp. 717-725.

78. Vasilevsky, I.V., Mezhdunarodnye obzori klinicheskaya praktika i zdorovje, Belarus, Minsk, 2017, pp. 147-159.

79. Guerranti, R., Bertocci, E., Fioravanti, A., and Papakostas, P., Int. J. Immunopathol. Pharmacol., 2010, vol. 23, no. 3, pp. 901-909.

80. Cavalli-Sforza, L.L., Menozzi, P., Piazza, A. in The History and Geography of Human Genes, PrincetonPrinceton University Press, 1994, pp. 1-108.

81. Langlois, M. and Delanghe, J., Clin. Chem., 1996, vol. 42, pp. 1589-6008.

82. Delanghe, J.R., Marijn, M., Speeckaert, M.M., and De Buyzere, M.L., Clin. Chem. Lab. Med. 2020, vol. 58, no. 7 , pp. $1125-1126$.

83. Nielsen, M.J., Petersen, S.V., Jacobsen, C., Oxvig, C., Rees, D., Møller, H.J., and Moestrup, S.K., Blood, 2006, vol. 108, no. 8, pp. 2846-2849.

84. Peacock, A.C., J. Natl. Cancer Inst., 1966, vol. 36, no. 4, pp. 631-639.

85. Nikolenko, O.V., Sudebno-medicinskay ekspertiza, 1977, vol. 3, pp. 45-47.

86. Pompach, P., Brnakova, Z., Sanda, M., Wu, J., Edwards, N., and Goldman, R., Mol. Cell. Proteomics, 2013, vol. 12, pp. 1281-1293.

87. Chen, C.B, Su, Y.C., Huang, T.T., Ho, H.C., Chang, Y.-T., Tung, Y.-T., and Lee, W.C., Clin. Chim. Acta, 2008, vol. 398, pp. 48-52.

88. Sanchez, J.-C., Appel, R.D., Golaz, O., Pasquali, C., Ravier, F., Bairoch, D F., and Hochstrasse, D.F., Electrophoresis, 1995, vol. 16, no. 7, pp. 1131-1151.

89. Bahk, Y.Y., Na, B.K. Cho, S.H., Kim, J.Y. Lim, K.-J., and Tong-Soo Kim, T-S., Korean J. Parasitol., 2010, vol. 48 , no. 3 , pp. 203-211.
90. Ma, H.T., Sriyam, S., Sinchaikul, S., Tsai, H.Y., Phutrakul, S., and Chen, S.-T., J. Proteomics Bioinform., 2013, vol. 6, no. 9, pp. 187-196.

91. Okano, T., Seike, M., Kuribayashi, H., Soeno, C., Ishii, T., Kida, K., and Gemma, A., Int. J. Oncol., 2016, vol. 48, no. 3, pp. 945-952.

92. Edelman, M.J., Hodgson, L., Rosenblatt, P.Y., Christenson, R.H., Vokes, E.E., Wang, X., and Kratzke, R.P.Y., J.Thorac. Oncol., 2012, vol. 7, no. 4, pp. 649-654.

93. Zhao, C., Annamalai, L., Guo, C., Kothandaraman, N., Koh, S.C.L., Zhang, H., Arijit Biswas, A., and Choolani, M., Neoplasia, 2007, vol. 9, no. 1, pp. 1-7.

94. Garibay-Cerdenares, O.L., Hernández-Ramírez, V.I., Osorio-Trujillo, J.C., Hernández-Ortíz, M., GallardoRincón, D., de León, D.C., Encarnación-Guevara, S., Villegas-Pineda, J.C., and Talamás-Rohana, P., J. Ovarian Res., 2014, vol. 7, 27.

https://doi.org/10.1186/1757-2215-7-27

95. Ye, B., Cramer, D.W., Skates, S.J., Gygi, S.P., Pratomo, V., Fu, L., Horick, N.K., Licklider, L.J., Schorge, J.O., Berkowitz, R.S., and Mok, S.C., Clin. Cancer Res., 2003, vol. 9, no. 8, pp. 2904-2911.

96. Chen, J., Cheuk I.W., Siu, M.T., Yang, W., Cheng, A.S., Shin, V.Y., and Kwong, A., Am J. Cancer Res., 2020, vol. 10, no. 9, pp. 2865-2877.

97. Bakrim, N.M., Mohd, S.A.N.S., Talib, A.N., Ab Rahman, J., and Abdullah, A., Malays J. Med. Sci., 2020, vol. 27, no. 2, pp. 64-76.

98. Chiappin, S., Antonelli, G., Gatti, R., and De Palo, E.F., Clin. Chim. Acta, 2007, vol. 383, nos. 1-2, pp. 30-40.

99. Zhang, X.L., Wu, Z.Z., Xu, Y., Wang, J.G., Wang, Y.Q., Cao, M.Q., and Wang, C.H., Open Chem., 2020, vol. 18, pp. 918-926.

100. Sun, L., Hu, S., Yu, L., Guo, C., Sun, L., Yang, Z., Qi, J., and Ran, Y., Int. J. Cancer, 2016, vol. 138, no. 11, pp. 2724-2731.

101. Kumar, D.M., Thota, B., Shinde, S.V., Prasanna, K.V., Hegde, A.S., Arivazhagan, A., Chandramouli, B.A., Santosh, V., and Somasundaram, K., J. Proteome Res., 2010, vol. 9, no. 11, pp. 5557-5567.

102. Petushkova, N.A., Zgoda, V.G., Pyatnitskiy, M.A., Larina, O.V., Teryaeva, N.B., Potapov, A.A., and Lisitsa, A.V., PLoS One, 2017, vol. 12, no. 5, e0177427. https://doi.org/10.1371/journal.pone.0177427

103. Okuyama, N., Ide, Y., Nakano, M., Nakagawa, T., Yamanaka, K., Moriwaki, K., Murata, K., Ohigashi, H., Yokoyama, S., Eguchi, H., Ishikawa, O., Ito, T., Kato, M., Kasahara, A., Kawano, S., Gu, J., Taniguchi, N., and Miyoshi, E., Int. J. Cancer, 2006, vol. 118, no. 11, pp. 2803-2808.

104. Ang, I.L., Poon, T.C.W., Lai, P.B.S., Chan, A.T.C., Ngai, S.-M., Hui, A.Y., Johnson, P.J., and Sung, J.J.Y., J. Proteome Res., 2006, vol. 5, no. 10, pp. 2691-2700.

105. Wu, D., Struwe, W.B., Harvey, D.J., Ferguson, M.A.J., and Robinson, C.V., Proc. Natl. Acad. Sci. USA, 2018, vol. 115, no. 35, pp. 8763-8768.

106. Park, S.Y., Lee, S.H., Kawasaki, N., Itoh, S., Kang, K., Ryu, S.H., Hashii, N., Kim, J.-M., Kim, J.-Y., 
and Kim, J.H., Int. J. Cancer, 2012, vol. 130, no. 10, pp. 2366-2376.

107. Hamrita, B., Chahed, K., Trimeche, M., Guillier, C.L., Hammann, P., Chaïeb, A., Korbi, S., and Chouchane, L., Clin. Chim. Acta, 2009, vol. 404, no. 2, pp. 111-118.

108. Nakano, M., Nakagawa, T., Ito, T., Kitada, T., Hijioka, T., Kasahara, A., Tajiri, M., Wada, Y., Taniguchi, N., and Miyoshi, E., Int. J. Cancer, 2008, vol. 122, vol. 10, pp. 2301-2309.

109. Hoagland, L.F.M., IV, Campa, M.J., Gottlin, E.B., Herndon, J.E., and Patz, E.F., Cancer, 2007, vol. 110, no. 10 , pp. $2260-2268$.

110. Lee, S.H., Jeong, S., Lee, J., Yeo, I.S., Oh, M.J., Kim, U., Kim, S., Kim, S.H., Park, S.-Y., Kim, J.-H., Park, S.H., Kim, J.H., and An, H.J., Mol. Biosyst., 2016, vol. 12, no. 12, pp. 3611-3621.

111. Kim, J.H., Lee, S.H., Choi, S., Kim, U., Yeo, I.S., Kim, S.H., Oh, M.J., Moon, H., Lee, J., Jeong, S., Choi, M.G., Lee, J.H., Sohn, T.S., Bae, J.M., Kim, S., Min, Y.W., Lee, H., Lee, J.H., Rhee, P.-L., Kim, J.J., Lee, S.J., Kim, S.T., Lee, J., Park, S.H., Park, J.O., Park, Y.S., Lim, H.Y., Won Ki Kang, W.K., An, H.J., and Kim, J.H., Oncotarget, 2017, vol. 8, no. 7 , pp. 11094-11104.
112. Miyoshi, E., Moriwaki, K., Terao, N., Tan, C.C., Terao, M., Nakagawa, T., Matsumoto, H., Shinzaki, S. and Kamada, Y., Biomolecules, 2012, vol. 2, no. 1, pp. 34-45.

113. Maresca, B., Cigliano, L., Spagnuolo, M.S., Piaz, F.D., Corsaro, M.M., Balato, N., Nino, M., Balato, A., Ayala, F., and Abrescia, P., PLoS One, 2012, vol. 7 , no. 12 , e52040. https://doi.org/10.1371/journal.pone.0052040

114. Nishino, K., Koda, S., Kataoka, N., Takamatsu, S., Nakano, M., Ikeda, S., Kamamatsu, Y., Morishita, R., Moriwaki, K., Eguchi, H., Yamamoto, E., Kikkawa, F., Tomita, Y., Kamada, Y., and Miyoshi, E., Oncotarget, 2018, vol. 9, no. 16, pp. 12732-12744.

115. Morishita, K., Maki, Y, Takamatsu, S., Ito, N., Koda, S., Kei Motooka, K., Kamada, Y., Kajihara, Y., and Miyoshi, E., Analytical Biochemistry, 2020, vol. 593,113588 . https://doi.org/10.1016/j.ab.2020.113588

116. Zhang, S., Shang, S., Li, W., Qin, X., and Liu, Y., Glycobiology, 2016, vol. 26, no. 7, pp. 684-692.

117. Tamara, S., Franc, V., and Heck, A.J.R., Proc. Natl. Acad. Sci. USA, 2020, vol. 117, no. 27, pp. 1555415564.

118. Dotz, V. and Wuhrer, M., FEBS Lett., 2019, vol. 593, pp. 2966-2976. 